\title{
Preliminary study of oil palm decanter cake natural polymer composite (OPDC-NPC)
}

\begin{abstract}
Palm oil industry produces huge amount of oil palm decanter cake (OPDC). Currently it is not yet commercialized however due to its characteristics, it can be used to produce oil palm decanter cake natural polymer composite (OPDC-NPC). NPC is a type of material made by combining natural fiber with polymer. Therefore the objective of this paper is to produce NPC from OPDC and then determine its mechanical and physical properties such as elasticity, stiffness, tensile strength and water absorption rate. The OPDC samples were collected from Felda Trolak Palm Oil Mill. Prior to NPC development, the oil was removed from OPDC using hexane soxhlet extraction method. OPDC-NPC was fabricated using molding method where the mixture of 95\% polypropylene (PP) and 5\% OPDC were mixed using twin-screw extruder. The results showed that OPDC-NPC has an elasticity of 2231 $\mathrm{MPa}$, stiffness of $30 \mathrm{MPa}$, tensile strength of $32 \mathrm{MPa}$ and water absorption rate of $0.16 \%$ which was slightly better with the other types of fibers.
\end{abstract}

Keyword: Natural polymer composite; Oil palm decanter cake; Palm biomass; Polypropylene 